\title{
Incorporation of nano-modified material in the production of smart concrete
}

\author{
Prakasit Sokrai ${ }^{1,{ }^{*}}$ and Natt Makul ${ }^{1}$ \\ ${ }^{1}$ EDP Department of Building Technology, Faculty of Industrial Technology, Phranakhon \\ Rajabhat University, 10220 Krung Thep Maha Nakhon, Thailand
}

\begin{abstract}
This article presented a review on the nano-modified smart concrete. Incorporating particles that are nanoscale in size into concrete may result in radically improved properties compared to concrete that has only conventional grain-size materials of the same chemical composition. Thus, it may be possible to re-engineer many existing products and to design new products that function at unprecedented levels and even in unprecedented ways.
\end{abstract}

\section{Introduction}

In the last decade, nano-research in construction has focused on investigating the structure of cement-based materials and their fracture mechanisms. With new advanced equipment it is possible to observe the structure at an atomic level and even to measure the strength, hardness, and other basic properties of the micro- and nano-scopic phases of materials. Besides, the incorporation of nanomaterials into the matrix with the purpose of improving the mechanical properties of concrete has emerged as a promising research field. Nanoscale particles are characterized by a high surface area-to-volume ratio and many are highly reactive, as shown in Fig. 1. A better understanding and more precise engineering of the extremely complex structure of cement-based materials at the nano-level are expected to result in a new generation of concrete that is stronger and more durable, with desirable stress-strain behavior and possibly possessing a range of newly introduced properties, such as electrical conductivity and temperature-, moisture-, and stress-sensing abilities. Nanobinders or nanoengineered cement-based materials with a nanosized cementitious component or other nanosized particles may be the next ground-breaking development [1].

Nanoparticles may be included in cementitious materials as spherical materials (e.g., nano- $\mathrm{SiO}_{2}$ (NS), nano- $\mathrm{TiO}_{2}(\mathrm{NT})$, nano- $\mathrm{Al}_{2} \mathrm{O}_{3}$ (NA), nano- $\mathrm{Fe}_{2} \mathrm{O}_{3}(\mathrm{NF})$, nano- $\mathrm{Fe}_{3} \mathrm{O}_{4}$, nano$\mathrm{ZnO}_{2}$, nano- $\mathrm{ZrO}$, nano- $\mathrm{Cu}_{2} \mathrm{O}_{3}$, nano-CuO, nano- $\mathrm{CaCO}_{3}$ ), as nanotubes or fibers (e.g., carbon nanotubes (CNT) and carbon nanofibers (CNF)), and as nano-clay (NC). However, in most research to date in this area the focus is on incorporating nano-silica (NS) in cementitious materials [2]. For example, when NS is added to cement grains, $\mathrm{H}_{2} \mathrm{SiO}_{4}{ }^{2-}$ forms and reacts with the available $\mathrm{Ca}^{2+}$, which forms additional calcium-silicate-hydrate (C-S-H) particles that spread in the water between the cement particles and serve as seeds

\footnotetext{
* Corresponding author: prakasit.s@pnru.ac.th
} 
for the formation of a more compact C-S-H phase. Unlike is the case with the pure $\mathrm{C}_{3} \mathrm{~S}$ as shown in Fig. 2 [3].

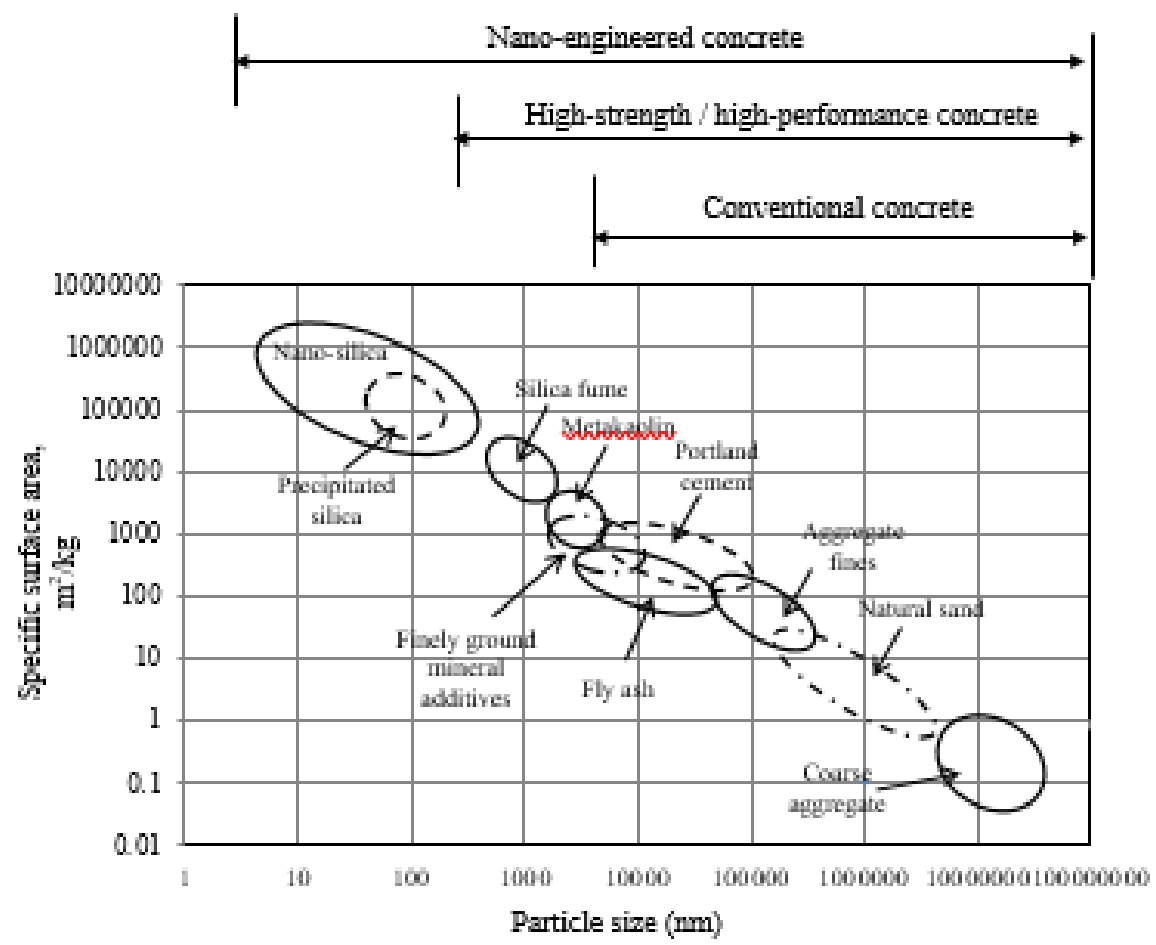

Fig. 1 Particle size and specific surface area related to concrete materials [4].

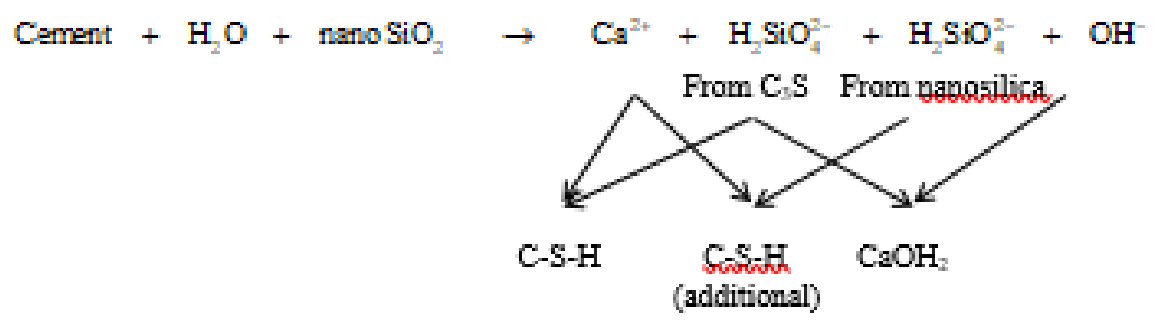

Fig. 2 Reaction mechanisms during the hydration of cement in presence of nanosilica [3].

\section{Smart concrete material}

Nano-engineering encompasses techniques whereby structures are manipulated at the nanometer scale with the purpose of creating a new kind of multi-functional cementitious composite that (i) is capable of delivering extremely high mechanical performance, (ii) boasts unprecedented durability properties, and (iii) offers the promise of solutions realized through autonomously directed functions such as self-sensing, -cleaning, and -healing. Concrete can be nano-engineered by incorporating nanosized items in order to control its behavior and provide a foundation for introducing useful new properties. Further, it is possible to nano-engineer concrete by incorporating molecules into cement particles and phases, aggregates, and additives, thereby creating possibilities for surface functionality such that the concrete can be manipulated to serve given purposes at the interface [5]. 

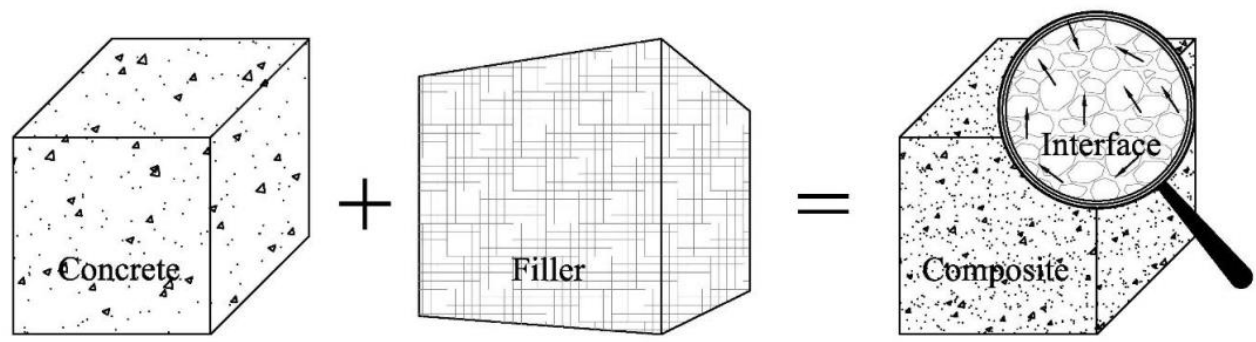

Fig. 3. Structure of Internal stress, strain, and cracks (ISSC) [6].

Self-sensing concrete (also called self-monitoring concrete, intrinsically smart concrete, and piezoresistive or pressure-sensitive concrete) is fabricated by adding function fillers (carbon fibers, steel fibers, carbon nanotubes, nickel powder, etc.) to standard concrete. The purpose and effect of doing this is to render concrete that is able to sense strain, cracking, or damage taking place in itself and to maintain and even improve its mechanical properties. Measuring the sensing property of self-sensing concrete is as crucial as processing such concrete. The sensing property of self-sensing concrete refers to the relationship between electrical and mechanical properties [6]. This smart material provides a basis for creating an intelligent infrastructure with multiple highly serviceable and value-adding functions such as health-monitoring or safety-monitoring abilities. Broadly speaking, self-sensing concrete enables a new approach to pursuing the production of sustainable concrete in concert with a range of functionalities. Internal stress, strain, and cracks (ISSC), for example, can accurately reflect internal stress, strain, cracks, and other kinds of damage and precursors to damage. ISSC, therefore, has potential applications in the fields of traffic detection and structural health monitoring (SHM) among many others [6]. Concrete can be transformed into a self-sensing instrument when a network of carbon nano-tubes (CNTs) is embedded in it, as shown in Fig. 3. By measuring changes in the electrical resistance of this network of CNTs wirelessly, the initiation and propagation of damage in concrete structures can be detected and monitored [4]. The self-sensing abilities of cementitious composites reinforced with well-dispersed CNTs and carbon nanofibers (CNFs) were the focus of a study by Konsta-Gdoutos and Aza (2014) [7]. The researchers experimentally established the electrical resistance of cementitious nanocomposites with a water-cement ratio of 0.3 reinforced with well-dispersed CNTs at $0.1 \mathrm{wt} \%$ and well-dispersed CNFs at $0.3 \mathrm{wt} \%$. They then compared the electrical resistance of these specimens with that of nanocomposites incorporating as-received nanoscale fibers at the same loading. The researchers demonstrated that conductivity measurements are an asset for assessing the smart properties of nanocomposites and that they may also provide a sound correlation between resistivity values and the extent to which materials are dispersed in the matrix. CNTs and CNFs incorporated at different loadings gave rise to lower electrical resistance. The nanocomposite specimens with CNTs at $0.1 \mathrm{wt} \%$ showed better electrical properties than did the specimens with CNFs included in the same proportion. Furthermore, conductivity measurements under cyclic compressive loading yielded information pertaining to the piezoresistive properties of some of the nanocomposites. The nanocomposites reinforced with $0.1 \mathrm{wt} \%$ CNTs and CNFs showed a greater change in resistivity, which suggests a higher level of sensitivity in the material in terms of strainsensing. In a study by ManiBharath et al. (2015) [8], self-sensing or smart behavior was observed in mortar or concrete with the addition of small amounts $(0.2$ to $0.5 \%$ by volume of cement) of short ( $5 \mathrm{~mm}$ in length) carbon fibers. An increase in electrical resistance was observed on loading up to crack propagation or fracture on reaching the inelastic stage, and 
the resistance change is not reversible. There was an increase in resistance during the fiber pull out in the elastic range. The change in elastic resistance, which was measured by a four-probe method, was shown to be reversible for elastic deformation. Also, the crack propagation and fiber breakage of the specimen can be identified by an irreversible change in resistance. The stress vs. strain and resistance vs. strain graphs were similar. This phenomenon can be used to determine the real-time weight of vehicles in traffic and the stress values of a loaded structure, as well as for damage assessment and health monitoring for static and dynamic loads. This method is not only easy to use, but also cheaper than either the strain gauge technique or the fiber optic technique, both of which are standard methodologies. The researchers presented results for each case as follows: For case (i), minimizing the cube size was shown to produce accuracy: a $50 \mathrm{~mm}$ cube was much better than a $70 \mathrm{~mm}$ cube for this reason. For case (ii), a $50 \mathrm{~mm}$ cube with copper wires wound along a stress axis was better than wires wound perpendicular to the stress axis. In case (iii), a $50 \mathrm{~mm}$ cube cured for 7 days was better than one subjected to curing for either 14 or 28 days - this result indicates that stress values in the field can be predicated successfully using carbon fibers, SF, and methyl cellulose together. For all three cases, a $50 \mathrm{~mm}$ cube with copper wires wound along the stress axis and subjected to curing for 7 days was better than the other mixes. Moreover, self-sensing cement-based composites are made by incorporating short fibers together with both micro- and nano-inclusions in the cementitious matrices, and the principal materials used for this purpose are carbon-based in nature given that they provide electrical conductivity. Self-sensing cement-based materials with MultiWalled Carbon Nano Tubes (MWCNTs) are considered to have great potential, as they can be used to convert a mechanical strain into a measurable variation of electrical resistance. D'Alessandro et al. (2016) [9] investigated various procedures for fabricating CNT-cement paste, mortar, and concrete. The CNTs were dispersed in water using chemical dispersants and various mixing strategies, whereas the quality of the CNT dispersion was assessed by measuring the rate of nanotube separation and by SEM inspections. Electrical percolation and strain-sensitivity were investigated in order to assess the quality of the fabricated composites. Based on the results, the researchers identified a processing procedure that, without sonication, might be effective for fabricating self-sensing cement-based composites in a way that is compatible with large-scale deployment. In particular, similar to observations related to sonicated specimens, the percolation thresholds of mortars and concretes fabricated with the scalable procedure were shown to be around $1 \%$ wt. of MWCNT content in respect to the weight of cement, whereas the same percolation threshold was less evident for pastes. The electrical conductivity and gauge factor of the same samples were also similar to those of the sonicated composites, whereby the conductivity of the composite paste, mortar, and concrete samples were assumed to have values of $5.2 \mathrm{E}-4,1.8 \mathrm{E}-4$, and $1.0 \mathrm{E}-4(\Omega \mathrm{cm})^{-1}$, respectively, and gauge factors of 130,68 , and 23 , respectively.

\subsection{Self-cleaning concrete}

A self-cleaning surface is defined as one that keeps itself clean through a natural phenomenon and without manual work. A hydrophobic or hydrophilic phenomenon is the approach most used to create a surface of this kind. Hydrophobic surfaces clean dirt based on the formation of water droplets, which remove dirt by rolling it away, whereas hydrophilic surfaces remove dirt through sheeting water, which directly carries away dirt. In recent years, photocatalysis has been used to photodecompose contaminants on the surfaces of buildings so that the contaminants deposited from polluted air are changed into washable mineralized compounds [10]. Concrete technology is the subject of continual development and improvement. Among the most recent contributions to improving the 
durability and sustainability of concrete is the addition of self-cleaning ability [11]. Selfcleaning concrete can decrease the presence of pollutants carried in the air and for this reason could become a widely used contributor to addressing contaminants in urban environments [12]. This effect is achieved by applying photocatalytic materials to a concrete mix [11]. Concrete-the defining material of the contemporary city environment - can be used to support environmental sustainability in far-reaching ways. For example, when photocatalytic $\mathrm{TiO}_{2}$ covers the concrete surface, there is potential for the concrete to become energized by ultraviolet (UV) radiation from the sun. In addition, organic particles that contribute to air pollution, e.g., $\mathrm{NO}_{\mathrm{x}}$, will decompose or change in some way such that pollution decreases. The result of this activity is that the concrete itself and the city environment more generally will become less contaminated and thus safer to live in. Yet, concrete has a rough surface, which means that it is not fully self-cleaning given that residues will remain (Fig. 4a). For this reason, more progress must be made before self-cleaning for concrete using photo-catalytic glass can be achieved. In cases where the surface is relatively smooth, though, such residues could be washed away by the rain (Fig. 4b).

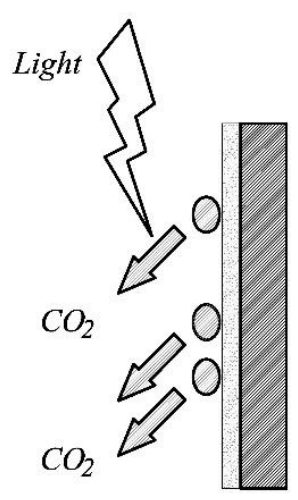

(a)

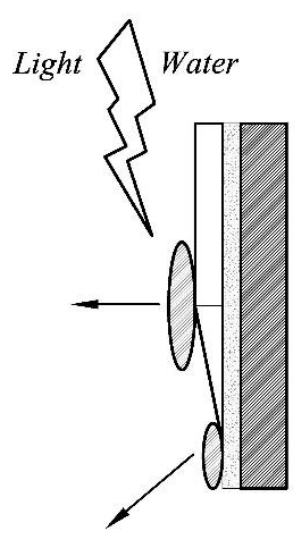

(b)

Fig. 4. Representation of concrete in self-cleaning activity: (a) ordinary concrete surface,(b) ultrasmooth concrete surface [12].

The self-cleaning and de-polluting ability of concrete arise from the photocatalytic properties of titanium dioxide, which can be incorporated into the building matrix. Nanoparticle anatase titanium dioxide exhibits photocatalytic properties when mixed with cementitious materials. Self-cleaning measurements show fast dye destruction kinetics. The cementitious materials show good activity related to $\mathrm{NO}_{\mathrm{x}}$ and BTEX and significant activity relating to realistic urban pollutants considered at common levels [13]. Dehn et al. (2005) [14] investigated the development of active catalytic coatings made of titanium dioxide fixed to concrete substrates. High-performance concrete was used as the substrate, and its performance was compared to that of the standard coating on glass. When an intermediate layer consisting of Levasil 200 or silicate paint is placed between the support and the $\mathrm{TiO}_{2}$, it is possible to achieve stable and highly active concrete surfaces. It appears that the effectiveness of the photocatalyst was not negatively influenced by any reaction between the concrete and the coating. Following a decade of development in Europe, a product of this kind called TX Active, which is a patented Portland cement developed by the Italcementi Group, has become available in North America. This product relies on 
photocatalytic components that draw on the energy from ultraviolet rays to oxidize most organic compounds as well as a number of inorganic compounds. These components remove air pollutants that ordinarily cause exposed surfaces to become discolored from the atmosphere, and any residue that remains after this process is washed away by rain. Thus, this product - this new kind of Portland cement - can be used in manufacturing concrete and plaster that lower the costs associated with maintenance and lead to a cleaner and safer city environment. Not only does this new product include Portland cement binders in its composition, but the current version of TX Active also includes photocatalytic titanium dioxide [15]. Awadalla et al. (2011) [16] studied the effects of using air-cleaning agents such as $\mathrm{TiO}_{2}$ on concrete composite panels that draw on local waste materials to reduce the presence of carbon dioxide $\left(\mathrm{CO}_{2}\right)$ in indoor-air buildings. Multiple factors are expected to determine the functioning and efficacy of the panels were considered, ranging from the extent of their porosity and types of waste materials to various percentages of $\mathrm{TiO}_{2}$ used in the mix design. The degradation process under laboratory conditions was studied using the chemiluminescence analysis method in order to measure the performance of photocatalytic active concrete products. The results showed that the photodegradation of $\mathrm{CO}_{2}$ was related to the porosity of the sample: when the porosity of the sample was increased, the $\mathrm{CO}_{2}$ cleaned pollutants from the air. Moreover, Kumar et al. (2013) [17] explored the feasibility of developing a self-cleaning cement surface. It has been observed that $\mathrm{TiO}_{2}$ nanoparticles retain their anatase form after doping with silver. A cement sample containing doped $\mathrm{TiO}_{2}$ showed better degradation efficiency than did cement samples with non-doped $\mathrm{TiO}_{2}$ for both sunlight and UV light. A cement slab with a $\mathrm{TiO}_{2}$ (doped with $0.2 \% \mathrm{Ag}$ ) to cement ratio of 0.2 showed the maximum degradation in the context of the study to be $76 \%$. $\mathrm{TiO}_{2}$ also enhanced the degree of whiteness of the white cement sample. $\mathrm{TiO}_{2}$-cement slabs with a $\mathrm{TiO}_{2}$ (doped with $2 \% \mathrm{Ag}$ ) to cement ratio of 0.2 showed maximum efficiency in regard to the degradation of color on the surface as compared to other samples. Subjecting white cement to $\mathrm{TiO}_{2}$ photocatalysis is an efficient way to create a self-cleaning cement surface that functions in a relatively straightforward way by benefiting from the effects of sunlight, oxygen in the air, and water via humidity and/or rain. Further, possible ways to advance and draw on the self-cleaning properties of cement nitrogen and carbon co-modified titaniabased $\left(\mathrm{TiO}_{2}-\mathrm{N}, \mathrm{C}\right)$ photocatalysts were investigated by Janus et al. (2015) [18]. The selfcleaning ability of prepared cement plates were evaluated by degrading a model organic compound (Reactive Red 198) under UV-vislight. It was found that the dye-degradation rate of the cement samples was dependent on the quantitative and qualitative composition of the material. Any increase in the photoactivity of the cement plates was primarily related to the crystallinity of the $\mathrm{TiO}_{2}-\mathrm{N}, \mathrm{C}$ additives, their carbon content, and presumably their nitrogen content. The specimens found to have the best self-cleaning ability were cement plates that contained $10 \mathrm{wt} \%$ of $\mathrm{TiO}_{2} / \mathrm{N}, \mathrm{C}-300$ photocatalyst after $100 \mathrm{~h}$ of UV-vislight irradiation.

Engineered cementitious composite (ECC) is a strain-hardening cementitious composite with extreme tensile ductility of several percent. Some emerging applications of ECC, including in lightweight building façades and pavement, make adding a self-cleaning function to this material desirable. Zhao et al. (2015) [10] studied the feasibility of imparting photocatalytic properties to ECC so that it could be rendered self-cleaning. The influence of $\mathrm{TiO}_{2}$ content on the mechanical properties, cleaning efficiency, surface wettability, and dirt-pick-up resistance of white ECC was studied. According to the results, the inclusion of $\mathrm{TiO}_{2}$ caused ECC to engage in photocatalysis, facilitated the decomposition of $\mathrm{RhB}$, and significantly enhanced the photo-induced hydrophilicity of ECC. Thus, $\mathrm{TiO}_{2}$ ECC was shown to be self-cleaning with greater dirt-pick-up resistance than that of normal ECC. However, $\mathrm{TiO}_{2}$ photocatalysis may adversely affect the flexural strength and ductility of ECC due to a weakened fiber-matrix interface bond after UV/sunlight irradiation. Shen 
et al. (2015) [12] investigated a photocatalytic concrete with an ultra-smooth surface produced via a novel method that relies on the nano-granular quality of $\mathrm{C}-\mathrm{S}-\mathrm{H}$, the cement's principal hydration product, and on the photocatalytic qualities of the $\mathrm{TiO}_{2}$ nanoparticles. The researchers found that the concrete surface was coated with a layer of $\mathrm{C}$ $\mathrm{S}-\mathrm{H}$ and $\mathrm{TiO}_{2}$ nano-particles at approximately $10 \mathrm{~nm}$, the surface roughness of the concrete was $3.5-11 \mathrm{~nm}$, and the surface of the photocatalytic ultra-smooth concrete is effective at degrading methylene blue (MB). The ultra-smooth surface and the concrete's photocatalytic qualities provide an environment in which the rain can remove any contaminant residue. Thus, this concrete presents significant possibilities as a self-cleaning material for the surfaces of city buildings. Moreover, self-cleaning cement materials were prepared by using electrolytic manganese residue (EMR) as a raw material in a study by Li et al. (2016) [20]. The flexural and compressive strength of the cement, which was produced by mixing $8 \%$ EMR, meets the national standard. In order to verify the self-cleaning properties of photocatalytic cement materials, model organic pollutants, such as MO dye, were subjected to degradation. The cement samples calcined at $500{ }^{\circ} \mathrm{C}$ for $2 \mathrm{~h}$ and coated for four cycles exhibited the best MO photodegradation efficiency of $94.2 \%$. The cement coated with $\mathrm{TiO}_{2}$ could be regenerated by calcination and then used repeatedly. A leaching test showed that the heavy-metal ion content was within the maximum limit set by the National Integrated Waste Water Discharge Standards in China (GB 8978-1996). The material developed in that study would be a good candidate for replacing Portland cement in the construction industry. It would certainly be beneficial from an environmental and economic viewpoint to use EMR in that context. In addition, thanks to nanotechnology, coatings comprising nanoparticles in liquid - that is, nanocoatings - can be fabricated. The nanoparticles are thoroughly dispersed in the liquid thereby realizing an extremely large surface area-volume ratio as a result of enhancing a number of the medium's properties. However, the most important characteristic of this nanocoating is its ability to self-clean [20].

\subsection{Self-healing concrete}

The concept of self-healing (also called self-repairing, autonomic-healing, and autonomic-repairing) refers to a material's ability to heal damage that it has sustained in an independent way. However, it is often the case that man-made materials referred to in any of these ways require an external trigger if they are to perform a self-healing action [21]. Self-healing materials are attracting increasing interest from the research community due to their efficiency in detecting and "autonomically" healing damage. Every year, numerous studies are published on developing various self-healing systems with the best possible properties and integrating them into large-scale production in a cost-effective way. Three kinds of materials have been proposed as self-healing agents in the very recent past: intrinsic self-healing, capsule-based self-healing, and vascular self-healing materials [23]. The creation of self-healing nanosystems with an extremely high level of performance is an important contemporary challenge for nanoscience and nanotechnology. The ability to selfheal is especially important for nanostructured systems given that they have a very high number of surface atoms, which means they tend to have multiple defects. In this context, researchers have noted that natural, most notably biological, systems can serve as inspiration in endeavors to design materials with the ability to self-heal [24]. Roig-Flores et al. (2015) [24] studied the self-healing effect of a crystalline admixture in the context of four kinds of environmental exposure and considered its performance in comparison with that of a control concrete specimen. The researchers investigated the extent to which healing had taken place by subjecting cracked specimens to permeability testing. Based on optic microscope observations, the researchers reported that cracks physically closed, and they also quantified the cracks based on geometrical parameters. The crack openings were 
shown to be less than $300 \mathrm{~lm}$, and the time taken to effect healing was 42 days. The healing behavior varied depending on the exposure and the presence of the crystalline admixture, which showed that water must be present if healing is to take place. Healing agent particles were coated with geopolymers following various mixture recipes in a study by de Koster et al. (2015) [26]. Metakaolin was used as an aluminosilicate source, and sodium silicate and sodium aluminate were used as activator liquids. The particles were coated by granulation in a low-shear granulator. In order to improve the coating process, the operating window and the granulation mechanism were determined for all the activator liquids used. Leaching and strength tests were performed, and the coated particles were incorporated into the cement paste in order to determine the feasibility of applying the particles in concrete as shown in Fig. 5. The results showed that the treated particles were better protected from leaching than the untreated particles were. The use of a high-pressure single-fluid nozzle to improve nebulization during the coating process produced more particles of the desired size than did coating with a low-pressure single-fluid nozzle with poor nebulization. Furthermore, the particles prepared with a high-pressure nozzle sprayer performed better when incorporated into the cement paste than did the particles prepared with a low-pressure nozzle sprayer.

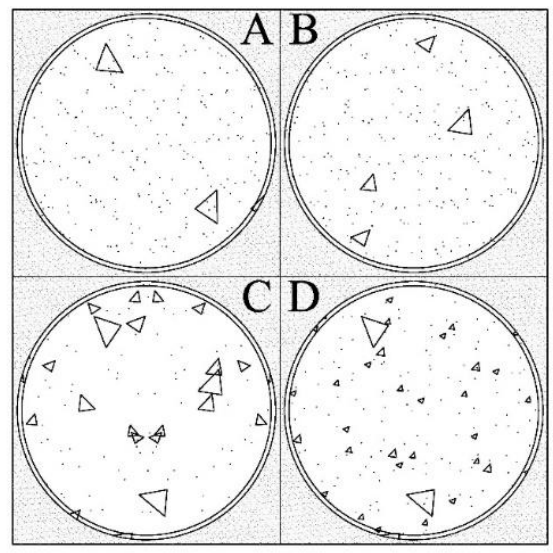

Fig. 5. Top view CT scans of (A) and (B) particles larger than $2 \mathrm{~mm}$ from batch 6, (C) particles between 1 and $2 \mathrm{~mm}$ from batch 1 and (D) agglomerates from batch 1 . In order to increase black saturation: cement paste (light grey), coating, healing agent and air (Triangle) [26].

To date, glass capsules, which are unable to withstand the mixing process of concrete, have been used predominantly in lab-scale proof-of-concept research on encapsulating polymeric agents in self-healing concrete. Hilloulin et al. (2015) investigated the design of polymeric capsules that have the ability to withstand the process whereby concrete is mixed but that may break when cracks occur. Three polymers, each of which had a low glasstransition temperature (Tg), were extruded: That is, poly(lactic acid) (PLA) $\left(\mathrm{Tg}=59{ }^{\circ} \mathrm{C}\right)$, polystyrene (PS) $\left(\mathrm{Tg}=102{ }^{\circ} \mathrm{C}\right)$ and poly(methyl methacrylate/n-butyl methacrylate) $(\mathrm{P}(\mathrm{MMA} / \mathrm{n}-\mathrm{BMA}))\left(\mathrm{Tg}=59^{\circ} \mathrm{C}\right)$. When the polymeric capsules were subjected to heating before being integrated with the rest of the mix such that their brittle condition gave way to a rubbery condition, their survival ratio became much higher than when they were not heated at this point. Moreover, part of the capsules that had remained intact during the concrete-mixing process broke with the occurrence of cracks. Processes of this nature are likely to yield positive results over time. However, steps must be taken to establish the parameters needed for optimization. A new type of phenol-formaldehyde (PF) shell/dicyclopentadiene (DCPD) core microcapsules was tested for the purpose of selfhealing microcracks in cementitious materials by synthesizing it via in-situ polymerization 
[19]. It was found that the mean diameter of the microcapsules could be controlled by adjusting the agitation rate during synthesis. This study shed light on the feasibility of selfhealing cementitious composites using this type of synthesized polymer microcapsule and contributed to the search for effective measures to reduce microcrack-induced damage sustained by cement-based structures. Additional research is needed to improve the bonding between the synthesized microcapsules and the cementitious matrix and to systematically evaluate healing efficiency and long-term performance. Further, Luo et al. (2015) [27] focused on developing a concrete capable of healing itself through a bacteria-based process. The researchers included a microbial self-healing agent that functioned principally through bacteria-induced mineral precipitations (calcite) in the concrete mix. Apparently an outcome of lamellar close-packing, calcite formed at the surface of the cracks, where it had a self-heating effect. However, the extent to which self-healing took place was related to several factors. For example, as the average width of the cracks increased, so did the difficulty of healing them. In fact, the microbial agent's success in healing applied only to cracks up to $0.8 \mathrm{~mm}$ wide. Water curing was shown to be the most effective approach to curing bacteria-based self-healing concrete. Further, the crack-healing ratio of specimens dropped dramatically as the age of the cracks advanced. At a cracking age of more than 60 days, the crack-healing ratio was very small. The results suggested that optimal conditions are required if the microbial self-healing agent is to be used in practice. Khaliq and Ehsan (2016) [27] also investigated the effects of using a microbial agent on the crack-healing ability of concrete. At the center of their study was the microbial activity of the bacteria, Bacillus subtilis. Bacteria were incorporated directly into the concrete through various carrier compounds, namely lightweight aggregate and graphite nano-platelets. In all the techniques implemented, calcium lactate was used as an organic precursor. Specimens were made for each mix to quantify the crack healing that took place and to compare changes in the compressive strength of the concrete. The results showed that bacteria immobilized in graphite nano-platelets gave better results in specimens pre-cracked at 3 and 7 days whereas bacteria immobilized in lightweight aggregates were more effective in samples pre-cracked at 14 and 28 days. In addition, concrete into which bacteria immobilized in lightweight aggregate had been incorporated also exhibited significant improvement in terms of compressive strength.

\section{Conclusions}

New developments have taken place in the nano-modified smart concrete of concrete; however, current challenges need to be solved before the full potential of nanotechnology can be realized in concrete applications, including proper dispersion; compatibility of the nanomaterials in cement; processing, manufacturing, safety, and handling issues; scale-up; and cost. The factors must be taken into consideration in developing nanotechnology for use in concrete. First, concrete and related products are bulk commodities. Even high value concrete structures require low materials costs and the ability to handle large quantities of material in a safe and environmentally acceptable manner. Second, innovations need to be thoroughly developed and field tested in order to build the knowledge and confidence in the construction community. Finally, concrete structures can be difficult to demolish, often requiring explosive or other high-energy approaches as an initial step to break up the major components of the structure. 


\section{Conflict of interest}

The author declares that there is no conflict of interest regarding the publication of this paper.

\section{References}

1. K. Sobolev, M. F. Gutiérrez, American Ceram. Soc. Bull. 84 14-18 (2005)

2. A. M. Rashad, Constr. Build. Mater. 52 437-464 (2014)

3. L. P. Singh, S. R. Karade, S. K. Bhattacharyya, M. M. Yousuf \& S. Ahalawat, A review. Constr. Build. Mater. 47 1069-1077 (2013)

4. B. Birgisson, A. K. Mukhopadhyay, G. Geary, M. Khan \& Sobolev, Nanotechnology in concrete materials: A synopsis. Transportation Research Circular E-C170. Transportation Research Board, Washington, United State of America (2012)

5. F. Sanchez, \& K. Sobolev, A review. Constr. Build. Mater. 24 2060-2071 (2010)

6. B. $\underline{\mathrm{Han}}, \mathrm{X} . \underline{\mathrm{Yu}}, \&$ J. $\underline{\mathrm{Ou}}$, Self-sensing concrete in smart structures. ButterworthHeinemann. Oxford, United Kingdom. (2014)

7. M. S. Konsta-Gdoutos \& C. A. Aza, Cem. Concr. Compos. 53 162-169 (2014)

8. S. M. Bharath, K. S. Sathyanarayanan, \& N. Sridharan,, International Conference on Engineering Trends and Science \& Humanities (ICETSH-2015). Tamilnadu, India (2015)

9. A. D’Alessandro, M. Rallini, F. Ubertini, A. L. Materazzi \& J. M. Kenny, Cem. Concr. Compos. 65(1), 200-213 (2016)

10. A. Zhao, J. Yang, E-K. Yang, Cem. Concr. Compos. 64 74-83 (2015)

11. H. Hunger, H. J. H. Brouwers, Excellence in Concrete Construction through Innovation (eds; Limbachiya and Kew). Taylor \& Francis Group, London, UK (2009)

12. W. Shen, C. Zhang, Q. Li, W. Zhang, L. Cao \& J. Ye, J. Clean. Prod. 87, 762-765 (2015)

13. F. Vallée, B. Ruot, L. Bonafous, L. Guillot, N. Pimpinelli, L. Casar, A. Strini, E. Mapelli, L. Schiavi, C. Gobin, H. André, N. Moussiopoulos, P. Papadopoulos, J. Bartzis, T. Maggos, R. McIntyre, C. Lehaut-Burnout, A. Henrichsen, P. Laugesen, R. Amadelli, D. Kotzias \& O. Pichat, O, PRO 41: International RILEM Symposium on EnvironmentConscious Materials and Systems for Sustainable Development (Edited; Kashino, N. and Ohama, Y.). RILEM Publications, France (2005)

14. F. Dehn, D. Bahnemann, \& B. Bilger, PRO 41: International RILEM Symposium on Environment-Conscious Materials and Systems for Sustainable Development (Edited Kashino and Ohama). RILEM Publications, France (2005)

15. M. Barbesta \& D. Schaffer, Photocatalytic cement helps oxidize pollutants. Conc. Int., 31-33 (2009)

16. A. Awadalla, M. F. M. Zain, A. A. H. Kadhum \& Z. Abdalla, Int. J. Phys. Sci. 6 67676774 (2011)

17. J. Kumar, A. Srivastava, \& A. Bansal, Int. J. Innov. Res. Sci. Eng. Technol. 2 26882693 (2013)

18. M. Janus, J. Zatorskaa, A. Czy'zewskia, K. Bubacza, E. Kusiak-Nejmana, A. W. Morawski, Appl. Surf. Sci. 330 200-206 (2015) 
19. L. Lv, Z. Yang, G. Chen, G. Zhu, N. Han, E. Schlangen, F. Xing, Constr. Build. Mater. 105, 487-495 (2016)

20. S. C. Pattanaik, In the Conference Proceedings of International Conference (ICTACE) Hyderabad (2011)

21. S. K. Ghosh, Self-healing materials: Fundamentals, design strategies, and applications. Wiley-Vch Verlag GmbH, Germany (2009)

22. D. G. Bekas, K. Tsirka, D. Baltzis \& A. S. Paipetis, Self-healing materials: A review of advances in materials, evaluation, characterization and monitoring techniques. Compos. Part B. 87 92-119 (2016)

23. V. Amendola \& M. Meneghetti, Self-healing at the nanoscale. Nanoscale. 1 74-88 (2009)

24. M. Roig-Flores, S. Moscato, P. Serna \& L. Ferrara, Build. Mater. 86 1-11 (2015)

25. S. A. L. Koster, R. M. Mors, H. W. Nugteren, H. M. Jonkers, G. M. H. Meesters \& J. R. van Ommen, Procedia Eng. 102 475-484 (2015)

26. M. Luo, C-X. Qian, \& R-Y. Li, Constr. Build. Mater. 87 1-7 (2015)

27. W. Khaliq \& M. B. Ehsan, Constr. Build. Mater. 102 349-357 (2016) 